\title{
Neonatal Group B Streptococcal Sepsis: Effects of Late Treatment with Dazmegrel
}

\author{
W. E. TRUOG, R. L. GIBSON, S. E. JUUL, W. R. HENDERSON, AND G. J. REDDING \\ Departments of Pediatrics and of Medicine, University of Washington School of Medicine, \\ Seattle, Washington 98195
}

\begin{abstract}
Neonatal group B streptococcal (GBS) sepsis produces pulmonary arterial hypertension and hypoxemia that are preventable by pretreatment with the selective thromboxane $A_{2}$ synthase inhibitor, dazmegrel. In the present experiment we administered dazmegrel $(8 \mathrm{mg} / \mathrm{kg})$ $2 \mathrm{~h}$ after the initiation of a $2 \frac{1 / 2}{\mathrm{~h}}$ infusion of $5 \times 10^{8} \mathrm{GBS} /$ $\mathrm{kg} / \mathrm{h}$ in ten 2- to 3-wk-old piglets. The multiple inert gas elimination technique was used to measure intrapulmonary shunt and alveolar ventilation to pulmonary perfusion mismatching. Thromboxane $B_{2}$, the stable metabolite of thromboxane $A_{2}$, and 6-keto-prostaglandin $F_{1 \alpha}$, the stable metabolite of prostacyclin, were assayed in arterial blood. Pulmonary arterial pressure increased immediately after initiation of the GBS infusion, rising from $12 \pm 2$ to $34 \pm$ 4 torr $(p<0.02)$; pulmonary vascular resistance increased by $400 \%(p<0.01)$. Arterial hypoxemia developed $(p<$ 0.02 ) in association with an increase in the low ventilationperfusion ratio index but without a significant increase in intrapulmonary shunt. Thromboxane $B_{2}$ levels increased 10-fold. Infusion of the carrier substance for dazmegrel after $2 \mathrm{~h}$ of GBS infusion produced no change in any variables. In contrast, infusion of the drug resulted in the return to pre-GBS infusion baseline values for both pulmonary arterial pressure and pulmonary vascular resistance. However, no improvement in arterial $\mathrm{pO}_{2}$ or in the low ventilation-perfusion ratio index occurred. Both pulmonary vascular resistance and pulmonary arterial pressure remained normal for $0.5 \mathrm{~h}$ after dazmegrel administration despite continued GBS infusion. Thromboxane $\mathbf{B}_{2}$ levels were decreased $30 \mathrm{~min}$ after dazmegrel $(p<0.02)$, but remained greater than pre-GBS levels. Dazmegrel reversed pulmonary hypertension and elevated pulmonary vascular resistance, but did so without concomitant improvement in pulmonary gas exchange, when administered after $2 \mathrm{~h}$ of GBS infusion. (Pediatr Res 23: 352-356, 1988)
\end{abstract}

\section{Abbreviations}

$\mathbf{P}_{\mathrm{pa}}$, pulmonary arterial pressure

PVR, pulmonary vascular resistance

GBS, group B streptococcus

$\dot{\mathbf{V}}_{\mathrm{A}} / \dot{\mathrm{Q}}$, ventilation-perfusion ratio

SVR, systemic vascular resistance

$T_{x} A_{2}$, thromboxane $A_{2}$

$T_{\mathbf{x}} B_{2}$, thromboxane $B_{2}$

$\mathbf{P G I}_{2}$, prostacyclin

$S D \dot{Q}_{p}, S D$ of pulmonary blood flow distribution

Received June 29, 1987; accepted December 1, 1987.

Correspondence William E. Truog, M.D., Professor of Pediatrics, Department of Pediatrics, RD-20, University of Washington School of Medicine, Seattle, WA 98195.

Supported in part by National Institutes of Health Grants HL 19187, HL 30542 (W.R.H.), and HL 01205 (W.E.T.)
$\dot{\mathrm{Q}}_{\mathrm{p}}$, pulmonary blood flow

AA, arachidonic acid

$\mathbf{P}_{\text {cwp }}$, pulmonary capillary wedge pressure

RIA, radioimmunoassay

cfu, colony-forming units

MIGET, multiple inert gas elimination technique

Intravenous infusion of GBS into a neonatal piglet results in acute derangements of both pulmonary gas exchange and pulmonary hemodynamics. An acute elevation in $\mathrm{P}_{\mathrm{pa}}$ and PVR develops with onset of GBS infusion (1-3). In addition, arterial hypoxemia develops because of mismatching of ventilation to perfusion characterized by increased $\dot{Q}_{p}$ to low $\dot{V}_{\mathrm{A}} / \dot{\mathrm{Q}}$ areas (3) and from depression of total $\dot{Q}_{p}$. Vasoactive metabolites of AA help mediate these events $(4,5)$. The pulmonary hemodynamic response to GBS in neonatal animals has been blocked or blunted by pretreatment or immediate post-GBS infusion treatment by the nonspecific cyclooxygenase inhibitor indomethacin (2), by the specific $T_{x} A_{2}$ synthase inhibitor dazmegrel (1), and by a competitive antagonist of sulfidopeptide leukotriene products of the 5-lipoxygenase pathway of AA metabolism, FPL 55712 (5).

Presently unknown is the extent to which AA metabolites, or other vasoactive substances $(6,7)$, sustain or aggravate the hemodynamic and gas exchange derangements during prolonged GBS infusion, and whether a thromboxane synthase inhibitor would alter the natural history of this process. Infusion of endotoxin from Escherichia coli (8) or live GBS (9) into adult sheep produces a two-phase response consisting initially of acute elevation in $\mathrm{P}_{\mathrm{pa}}$ and PVR, followed in 2-3 h by increased pulmonary lymph flow, but with a partial decline toward baseline values in $P_{p a}$ and PVR.

We have previously shown that levels of $T_{x} B_{2}$, the relatively inactive metabolite of the potent vascoconstrictor $T_{x} A_{2}$, remain elevated up to $1 \mathrm{~h}$ after the end of an infusion of GBS (1). We hypothesized that elevated $\mathrm{TxA}_{2}$, produced in response to continuing GBS infusion, is associated with sustained pulmonary arterial hypertension and $\dot{\mathrm{V}}_{\mathrm{A}} / \dot{\mathrm{Q}}$ mismatching. We further hypothesized that inhibition of ongoing synthesis of $T_{x} A_{2}$ should result in improvement in both hemodynamic and gas exchange variables during established GBS bacteremia due to decreased $\mathrm{P}_{\mathrm{pa}}$ and improved $\dot{\mathrm{V}}_{\mathrm{A}} / \mathrm{Q}$ matching.

\section{METHODS}

Animal preparation. Fifteen healthy piglets, age 14-21 days, were anesthetized with pentobarbital $(25 \mathrm{mg} / \mathrm{kg}$ intravenously then $5 \mathrm{mg} / \mathrm{kg} / \mathrm{h}$ ). The animals underwent tracheostomy placement. Pulmonary arterial and systemic arterial catheters were then inserted. An additional double-lumen intravenous catheter was introduced for infusion of inert gases (mixed in $D_{5} W$ in 
normal saline and infused at a rate of $5 \mathrm{ml} / \mathrm{kg} / \mathrm{h}$ ). After instrumentation the animals were paralyzed (pancuronium $0.1 \mathrm{mg}$ / $\mathrm{kg}$ ) and received assisted ventilation (Harvard Apparatus, Millis, MA) with room air as the inspired gas and frequency established to maintain an arterial $\mathrm{pCO}_{2}$ of 35-40 torr. The animals were inflated with a tidal volume of twice normal three times in succession, 10-15 min before each experimental manipulation to minimize spontaneous atelectasis.

Heparinized saline $(5 \mathrm{ml} / \mathrm{h})$ was administered continuously via the pulmonary arterial catheter except during pressure recordings. All vascular pressure measurements were recorded at end expiration. Animal temperature was maintained with a heating blanket and an overhead warmer as needed to maintain arterial temperature at $38.5 \pm 0.5^{\circ} \mathrm{C}$. Animals had their urinary bladders drained as needed during the experimental protocol.

Minute ventilation was calculated as previously described (10). Total $\dot{\mathrm{Q}}_{\mathrm{p}}$ was calculated by the thermodilution technique (11). An index of PVR was calculated according to the formula PVR $=\mathrm{P}_{\mathrm{pa}}-\mathrm{P}_{\mathrm{cwp}} \div \dot{\mathrm{Q}}_{\mathrm{p}}$. An index of systemic vascular resistance was calculated by dividing mean systemic arterial pressure by $Q_{p}$, assuming $\dot{\mathrm{Q}}_{\mathrm{s}}=\dot{\mathrm{Q}}_{\mathrm{p}}$.

Arterial and mixed venous blood gas tensions and $\mathrm{pH}$ were measured within two minutes of sampling (Corning 165 Blood Gas Analyzer).

Assessment of ventilation perfusion matching. The multiple inert gas elimination technique (12) was used as previously described $(1,3)$ to assess intrapulmonary shunt and distribution of $\dot{V}_{A} / \dot{Q}$ ratios. A unitless index of overall ventilation perfusion heterogeneity, separate from shunt (perfusion to areas of zero ventilation) and dead space (ventilation to areas of zero perfusion) was assessed using the derived variable $\operatorname{SDQ}_{p}(13,14)$ Special care was taken to maintain constant hematocrit and animal temperature during the experimental protocol in order to prevent fluctuations in the blood-gas partition coefficient for each inert gas (15).

Bacterial preparation. Group B $\beta$-hemolytic streptococci, type III, were prepared as previously described $(1,3)$. Bacteria were incubated for $18 \mathrm{~h}$ before each experiment in Todd Hewitt broth. The broth culture was then centrifuged and final concentration of the bacteria in saline suspension was calculated on each experimental day, using a previously determined plot relating bacterial cfu to optical density.

Assessment of arachidonate metabolites. At each sampling time in the 10 experimental animals, a 2-ml sample of arterial blood was obtained as previously described (1). The sample was drawn directly into cold inhibitor solution containing indomethacin and sodium EDTA. Samples were centrifuged at $15000 \mathrm{rpm}$ $\times 10$ min and the decanted fluid was frozen and stored at $-70^{\circ}$ $\mathrm{C}$ until RIA for $\mathrm{T}_{\times} \mathrm{B}_{2}$ and 6-keto-PGF ${ }_{1 \alpha}$, the stable hydrolysis products of $T_{x} A_{2}$ and $P_{2} I_{2}$, respectively, was performed (WRH). Immediately before RIA, samples were deproteinated using ultrafiltration. Matrix effects due to protein present in unknown piglet plasma samples were determined in standard curves run in eicosanoid-free piglet plasma prepared by charcoal stripping. Samples were analyzed in duplicate according to standard protocol $(16,17)$. The values for 6 -keto- $\mathrm{PGF}_{1 \alpha}$ and $\mathrm{T}_{\mathrm{x}} \mathrm{B}_{2}$ are expressed as the average of the two values obtained with each analysis. $\mathrm{T}_{\mathrm{x}} \mathrm{B}_{2}$ and 6-keto-PGF $\mathrm{PG}_{1 \alpha}$ were assayed by the measurement of competitive inhibition of ${ }^{3} \mathrm{H} \mathrm{T}_{\mathrm{x}} \mathrm{B}_{2}$ to anti- $\mathrm{T}_{\mathrm{x}} \mathrm{B}_{2}$ and ${ }^{3} \mathrm{H}$ 6-keto-PGF $F_{1 \alpha}$ to 6-keto-PGF $F_{1 \alpha}$ binding, respectively. The $\mathrm{T}_{\mathrm{x}} \mathrm{B}_{2}$ or 6-keto-PGF $F_{1 \alpha}$ was conjugated to porcine thyroglobulin by the mixed anhydride method before immunization of the rabbits. The anti- $\mathrm{T}_{\mathrm{x}} \mathrm{B}_{2}$ and anti-6-keto-PGF ${ }_{1 \alpha}$ antisera were produced in rabbits by the method of Jaffe and Behrman (18). The anti-TxB antiserum at a dilution of $1: 100,000$ had a sensitivity of $1 \mathrm{pg} / 0.1$ $\mathrm{ml}$ sample and the following cross-reactivities at $\mathrm{B} / \mathrm{Bo} 50 \%$ : $\mathrm{PGD}_{2}, 0.53 \%$; $\mathrm{PGF}_{2 \alpha}, 0.20 \%$; $\mathrm{PGF}_{1 \alpha}, 0.02 \%$; and $\mathrm{PGE}_{2}, 6$-keto$\mathrm{PGF}_{1 \alpha}$, and 6-keto-PGE 1 each less than $0.02 \%$. The anti-6-keto$\mathrm{PGF}_{1 \alpha}$ antiserum at a dilution of $1: 2,000$ had a sensitivity of 10 $\mathrm{pg} / 0.1 \mathrm{ml}$ and the following cross-reactivities at B/Bo 50\%: 6-
keto-PGE $1,2.5 \% ; \mathrm{PGF}_{1 \alpha}, 1.43 \% ; \mathrm{PGF}_{2 \alpha}, 0.77 \% ; \mathrm{PGD}_{2}, 0.42 \%$; and $\mathrm{T}_{x} \mathrm{~B}_{2}, \mathrm{PGE}$, and $\mathrm{PGE}_{2}$ each less than $0.11 \%$. Labeled tracers $\left({ }^{3} \mathrm{H} \mathrm{T}_{\mathrm{x}} \mathrm{B}_{2}\right.$ and ${ }^{3} \mathrm{H}$ 6-keto-PGF ${ }_{1 \alpha}$ ) were obtained (New England Nuclear Research Products, Boston, MA). Unlabeled, synthetic standards were the generous gift of Douglas McCarter (Upjohn Co, Kalamazoo, MI).

Preparation of dazmegrel. Dazmegrel (UK 38, 485) $(8 \mathrm{mg} / \mathrm{kg}$ ) was dissolved just before infusion in $1.0 \mathrm{ml}$ of $0.1 \mathrm{~N} \mathrm{NaOH}$ to which was added $0.9 \%$ saline to make a $5 \mathrm{ml}$ solution. Sham injections consisted of the same volume of $\mathrm{NaOH}$-saline solution without the drug.

Experimental protocol. After instrumentation and collection of baseline samples, each animal received an infusion of 5 to 8 $\times 10^{8} \mathrm{cfu} / \mathrm{kg} / \mathrm{h}$ of live GBS. In five animals, the GBS infusion was continued for $3 \mathrm{~h}$ without further intervention in order to establish an infusion rate of GBS which would provide prolonged, sustained elevation of $\mathrm{P}_{\mathrm{pa}}$ and PVR without inducing systemic hypotension or metabolic acidosis.

In the 10 study animals, GBS was infused for $2.5 \mathrm{~h}$, with blood samples and hemodynamic measurements recorded at $30 \mathrm{~min}$ and $2 \mathrm{~h}$ after initiation of the infusion. After the 2-h sampling, a sham injection of $\mathrm{NaOH}$-saline mixture was administered to detect any effect on pulmonary hemodynamics of the carrier substance for dazmegrel. Ten min later, $8 \mathrm{mg} / \mathrm{kg}$ of dazmegrel in the same carrier was administered. Twenty min after the end of dazmegrel administration, while the GBS infusion continued, a fourth set of samples was obtained, Hemodynamic measurements were continued for $30 \mathrm{~min}$ after the end of the bacterial infusion which had been continued for $30 \mathrm{~min}$ after the infusion of dazmegrel. Animals were then killed and the lungs promptly removed, inspected for areas of atelectasis, and wet and dry lung weights were obtained by methods previously described (19).

Statistics. The paired $t$ test was used to compare the $2 \mathrm{~h}$ GBS and the postdazmegrel samples to baseline data. A $p$ value of $<0.05$ was used for establishing significance. The nonparametric Mann Whitney $U$ test was used for analysis of inert gas data (20).

\section{RESULTS}

The results of the continuous infusion of GBS in the five pilot animals are shown in Figure $1 A$ and $B . \mathrm{P}_{\mathrm{pa}}$ and PVR both increased with the onset of GBS infusion (Fig. $1 A$ ) and remained elevated throughout the course of the infusion. Arterial $\mathrm{pO}_{2}$ (Fig. $1 B$ ) declined shortly after initiation of the infusion and hypoxemia persisted throughout the 3 -h period. There was no change in $\mathrm{pH}$ or $\mathrm{pCO}_{2}$ during the course of the infusion. Neither mean systemic arterial pressure nor systemic vascular resistance changed in these five animals during the 3 -h period.

Hemodynamic data for the 10 animals receiving dazmegrel at $2 \mathrm{~h}$ postinitiation of the GBS infusion are illustrated (Figs. 2-4). A prompt decline in $\mathrm{P}_{\mathrm{pa}}$ (Fig. 2) and PVR (Fig. 4) occurred with dazmegrel infusion. There was a small increase in $\dot{Q}_{p}$ after dazmegrel (Fig. 3). Arterial $\mathrm{pO}_{2}$ results are illustrated (Fig. 5, top); there was no increase in $\mathrm{PaO}_{2}$ after dazmegrel administration. The percentage of intrapulmonary shunt and $\mathrm{SDQ}_{\mathrm{p}}$ at each experimental time is also shown (Fig. 5, bottom); a sustained increase in $S D \dot{B}_{p}$ occurred with no significant effect on shunt with GBS infusion; this did not diminish with dazmegrel. No change in SVR, $\mathrm{pH}$, or $\mathrm{pCO}_{2}$ occurred in these 10 animals during any of the experimental conditions. Also, there was no change in peak airway pressure recorded at any of the experimental times.

The results of arterial $\mathrm{T}_{\mathrm{x}} \mathrm{B}_{2}$ and 6-keto-PGF $\mathrm{PG}_{1 \alpha}$ measurements are shown in Figure 6 . As expected, $\mathrm{TxB}_{2}$ increased significantly with the onset of the GBS infusion. There was a decrease in $T_{x} B_{2}$ levels $30 \mathrm{~min}$ after the administration of dazmegrel but $T_{x} B_{2}$ did not decline back to pre-GBS values. In contrast, 6-keto-PGF ${ }_{1 \alpha}$ continued to be elevated even after the infusion of dazmegrel.

The mean $( \pm S D)$ dry weight to wet weight ratio for the five 

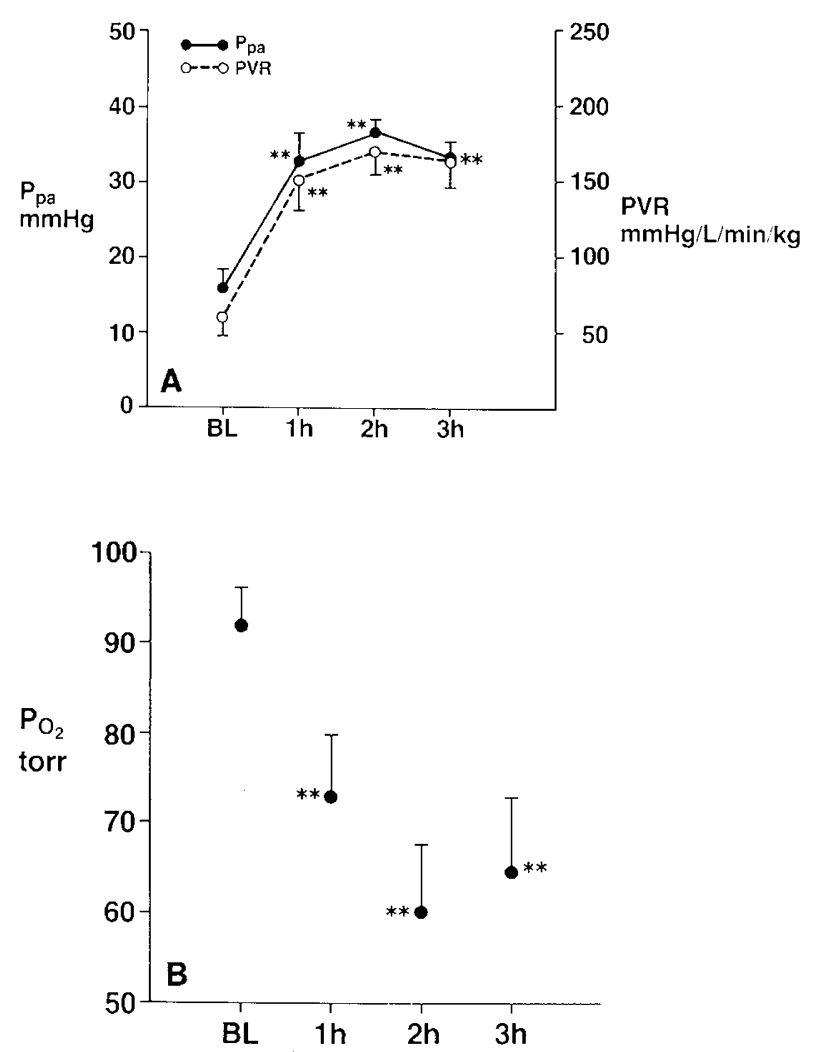

Fig. 1. $A, \mathrm{P}_{\mathrm{pa}}$ and PVR are plotted against time of GBS infusion for five animals who received a continuous infusion. $B$, arterial $\mathrm{pO}_{2}$ is plotted against time of GBS infusion for five animals who received a continuous infusion of bacteria. Data shown as mean $\mathrm{X} \pm 1 \mathrm{SD} . B L$, baseline. ${ }^{* *} p$ $<0.02$ compared to baseline.

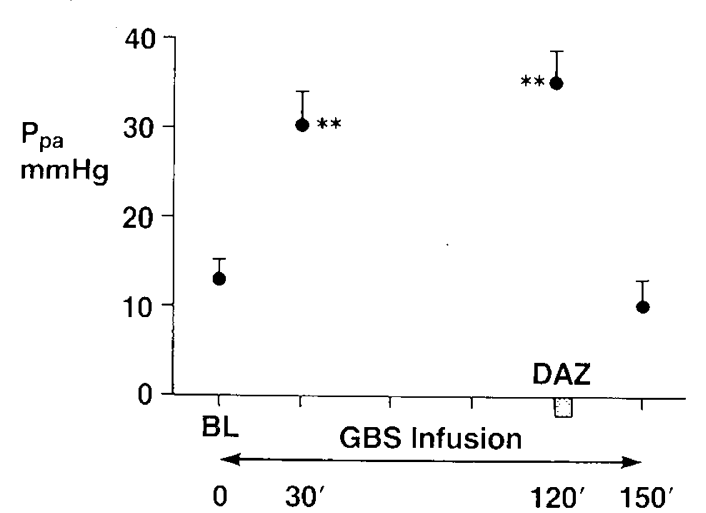

Fig. 2. Pulmonary arterial pressure is plotted against time for the 10 animals who received dazmegrel $(d a z)$. Duration of infusion is shown on the abscissa. $B L$, baseline. ${ }^{* *} p<0.02$ compared to baseline data.

animals that received a $3-\mathrm{h}$ GBS infusion was $0.19 \pm 0.11$. The dry to wet weight ratio was $0.188 \pm 0.04$ for the 10 experimental animals. These data are similar to those found in piglets similarly instrumented but not subjected to GBS infusion (21).

Infusion of the carrier substance for dazmegrel without the active drug caused no detectable change in any of the pulmonary or systemic hemodynamic data or in gas exchange measurements.

\section{DISCUSSION}

This study demonstrated that administration of dazmegrel $2 \mathrm{~h}$ after the onset of pulmonary arterial hypertension and arterial hypoxemia induced by GBS infusion in a neonatal animal resulted in prompt decline in $\mathrm{P}_{\mathrm{pa}}$ and PVR to baseline levels where

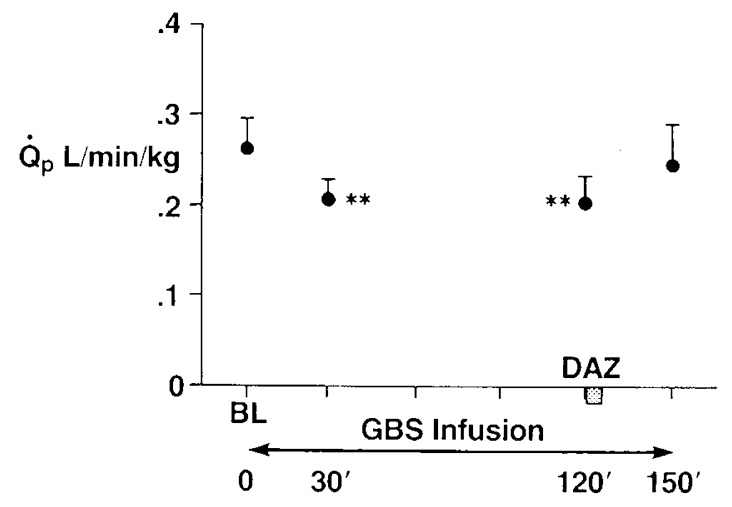

Fig. 3. $\dot{Q}_{p}$ is plotted against time for the 10 experimental animals. Abbreviations are the same as in Figure 2. ${ }^{* *} p<0.02$.

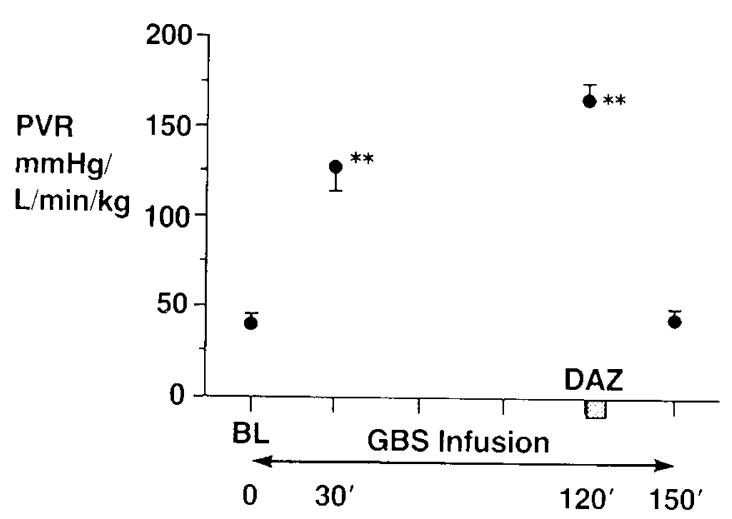

Fig. 4. PVR is plotted against time. Abbreviations are the same as in Figure 2. ${ }^{* *} p<0.02$.
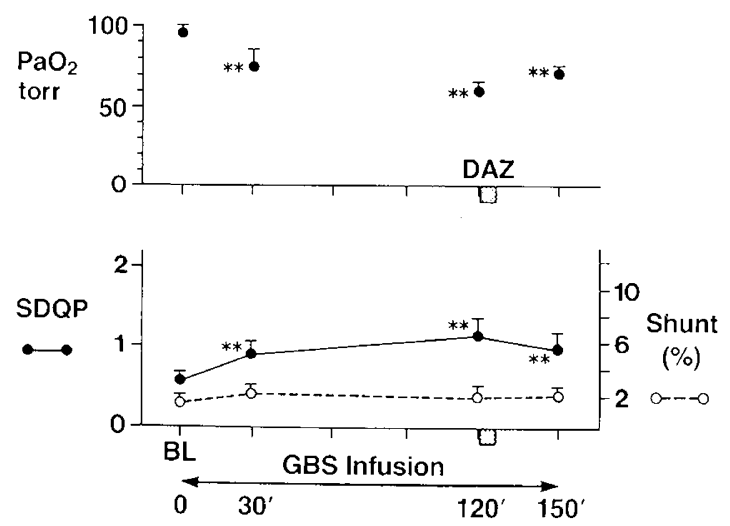

Fig. 5. Arterial $\mathrm{PO}_{2}$ is plotted against time (top). The $\mathrm{SDQ}_{\mathrm{p}}$ and \% intrapulmonary shunt are plotted respectively on the left and right ordinate against time (bottom). Abbreviations are the same as in Figure 2. ${ }^{* *} p<0.02$ compared to baseline.

they remained for at least $0.5 \mathrm{~h}$ after the administration of dazmegrel during ongoing bacterial infusion. The hemodynamic results are analagous to the results obtained with treatment with dazmegrel before bacterial infusion (1). In contrast, there was no concomitant improvement in pulmonary gas exchange as assessed by both respiratory gas tensions and by tracer inert gas analysis to evaluate matching of alveolar ventilation to pulmonary perfusion.

Our results suggest that delayed treatment with dazmegrel resulted in a decrease in $\mathrm{P}_{\mathrm{pa}}$ without any improvement in pulmonary gas exchange, in contrast to the finding of a $<5$ torr mean decrease in $\mathrm{PaO}_{2}$ during GBS infusion in animals pretreated with daz (1) and a decrease of 17 torr (1) to 40 torr $(2,3)$ when GBS was infused into control animals during ambient air 


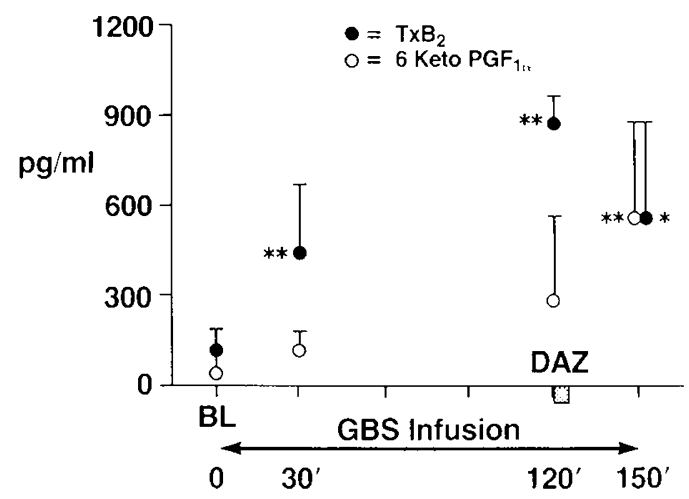

Fig. 6. $\mathrm{TxB}_{2}$ and 6-keto $\mathrm{PGF}_{1 \alpha}$ are plotted against time. Abbreviations are the same as in Figure 2. ${ }^{*} p<0.05 ;{ }^{* *} p<0.02$.

breathing. There are two possible reasons why arterial $\mathrm{pO}_{2}$ failed to improve when $T_{x} A_{2}$ synthesis was inhibited and PVR was diminished with dazmegrel treatment. Animals may have developed substantial interstitial or alveolar edema after $2 \mathrm{~h}$ of bacterial infusion and pulmonary hypertension, which would result in mismatched $\dot{\mathrm{V}}_{\mathrm{A}} / \dot{\mathrm{Q}}$. Julien et al. (22) tested whether changes in lung wet weight to dry weight ratios accurately reflected edema development, by creating two different forms of pulmonary edema, induced by increased hydrostatic pressure and by oleic acid infusion. All animals had significant increases in wet weight to dry weight ratios compared to nonmanipulated animals. In contrast in our study, the dry to wet weight ratio data obtained from animals infused with GBS, as well as experimental animals posttreated with dazmegrel, are similar to data obtained from control piglets in other laboratories (21). However, relatively small changes in edema may contribute to the decrease in arterial oxygen tension (23).

An additional cause of hypoxemia in this setting may be that the selective $T_{x} A_{2}$ synthase inhibitor resulted in an unbalanced vasodilator effect of $\mathrm{PGI}_{2}$, measured as 6-keto-PGF ${ }_{1 \alpha}$. $\mathrm{PGI}_{2}$ has been demonstrated to sustain pulmonary blood flow to hypoxic lung regions, overcoming local hypoxic pulmonary vasoconstriction (24). If a small amount of alveolar edema had already formed, creating poorly ventilated lung regions, continuing pulmonary blood flow to these otherwise vasoconstricted regions would produce an increase in $\mathrm{SDQ}_{\mathrm{p}}$ after $2 \mathrm{~h}$ of GBS infusion. The lack of change in SVR, mean systemic arterial pressure, or systemic $\mathrm{pH}$ suggests that these are local effects occurring only in the lung. The prompt fall in $\mathrm{P}_{\mathrm{pa}}$ without improvement in arterial $\mathrm{pO}_{2}$ also suggests that the elevated PVR was not primarily due to hypoxic pulmonary vasoconstriction in this model.

The decline in $\mathrm{P}_{\mathrm{pa}}$ occurred while thromboxane levels remained elevated, as assessed by the $T_{x} A_{2}$ metabolite, $T_{x} B_{2} . T_{x} B_{2}$ has been used as an index of $T_{x} A_{2}$ production because it is a stable metabolite of $T_{x} A_{2} \cdot T_{x} B_{2}$ itself has only minimal vasoconstrictive activity. However, recent studies have questioned the role of $T_{x} B_{2}$ measurements as a marker of thromboxane activity, as this substance is derived nonenzymatically from the breakdown of $T_{x} A_{2}(25,26)$. Thus, $T_{x} B_{2}$ can be readily generated from $\mathrm{T}_{\mathrm{x}} \mathrm{A}_{2}$, even with careful drawing of blood into an inhibitor mixture (25). Others (26) have used the enzymatically derived metabolite 11 dehydro- $T_{x} B_{2}$ as a more sensitive reflection of $T_{x} A_{2}$ production. However, the highly significant increases in $T_{x} B_{2}$ in response to GBS infusion and the sharp decline in circulating $T_{x} B_{2} 30$ min after dazmegrel administration likely reflect physiologically important changes. Levels of 6-keto$\mathrm{PGF}_{1 \alpha}$, the inactive metabolite of the vasodilator prostacyclin, increased throughout the GBS infusion period, especially after dazmegrel infusion. This may have occurred because of "shunting" of the precursor-product reaction in the direction of this metabolite or it may have occurred in direct response to GBS infusion without regard to inhibition of the $T_{x} B_{2}$ synthetic path- way. We previously found an insignificant change in $\mathrm{PGI}_{2}$ levels during GBS infusion (1), although Runkle et al. (2) found an increase in both $T_{x} B_{2}$ and $\mathrm{PGI}_{2}$ during GBS infusion. The effect of a prolonged infusion of GBS into neonatal animals followed by dazmegrel treatment on $\mathrm{PGI}_{2}$ levels had not been reported before our study.

The MIGET provides quantitative data about the range of $\dot{\mathrm{V}}_{\mathrm{A}} /$ $\dot{Q}$ distributions in the lung $(12,14)$. The technique allows precise measurement of intrapulmonary shunt and anatomical dead space and semiquantative measurements of intermediate $\dot{V}_{A} / \dot{Q}$ distributions. As originally described, the technique used a theoretical 50-compartment lung model, one compartment representing shunt, another dead space, and the remaining 48 compartments were assigned a $\dot{\mathrm{V}}_{\mathrm{A}} / \dot{\mathrm{Q}}$ ratio equally spaced along a logarithmic scale (12). Because the lung models had more compartments than there were pieces of data available, the equations predicting fractional $Q_{p}$ and $V_{A}$ to each compartment were underdetermined and had nonunique solutions. However, mathematical analysis of the technique provides evidence that within the bounds of physiologically possible results, i.e. constraint of nonnegative blood flow to each compartment, all the possible solutions are nearly identical (27). The MIGET was used herein to provide a quantitative measurement of intrapulmonary shunt and $\dot{\mathrm{V}}_{\mathrm{A}} / \dot{\mathrm{Q}}$ mismatching separate from shunt. The index of $\dot{\mathrm{V}}_{\mathrm{A}} /$ $\dot{Q}$ mismatching, the $\log S_{D} \dot{Q}_{p}$, provides a semiquantitive estimate of the extent of mismatching of $\dot{V}_{A}$ to $\dot{Q}$ in lung regions that are both perfused and ventilated. The $S D \dot{Q}_{p}$ summarizes $\dot{\mathrm{V}}_{\mathrm{A}} / \mathrm{Q}$ heterogeneity detected by the 50 -compartment model yet avoids the uncertainty inherent in assigning a specific fraction of the total $\dot{\mathrm{Q}}_{\mathrm{p}}$ to a particular $\dot{\mathrm{V}}_{\mathrm{A}} / \dot{\mathrm{Q}}$ region. $\mathrm{SDQ} \dot{\mathrm{p}}_{\mathrm{p}}$ agrees experimentally with other indices of $\dot{V}_{A} / Q$ maldistribution that have been derived from MIGET data (28). Overall reproducibility of MIGET has recently also been shown to be very satisfactory (29).

Neonatal piglets can serve as a reasonable model of neonatal GBS sepsis based on similar postnatal pulmonary vascular morphometric features $(30,31)$. However, extrapolation of results obtained in this or other animal studies to human newborns should be done cautiously. This study does suggest that multiple vasoactive mediators derived from arachidonic acid may participate in sustaining or aggravating the various pathophysiologic mechanisms present after hours of GBS sepsis and helps define the pathophysiologic role of $\mathrm{T}_{x} \mathrm{~A}_{2}$, even in "late" sepsis. Leukotrienes $\mathrm{C} 4$ and $\mathrm{D} 4$, products of the 5-lipoxygenase pathway of AA metabolism, have recently been demonstrated to be important in early experimental GBS sepsis (4) and in idiopathic persistent pulmonary hypertension in the newborn (32). Other vasoactive substances, such as tumor necrosis factor (33), may also contribute to sepsis-associated pulmonary pathology. Step by step analysis of the effects of specific blocking agents on the end metabolites of the various AA metabolic pathways should help establish their relative causative importance in the hemodynamic and gas exchange abnormalities occurring with GBS infusion.

Acknowledgments. The authors acknowledge the technical assistance of Olivia Acuna, Richard Tuck, and Paul Lehman, and the secretarial assistance of Jo Ann Jarrett and Kathi Young. The authors also acknowledge the gift of the dazmegrel by Dr. R. Urguilla, Pfizer Central Laboratories, Groton, CT.

\section{REFERENCES}

1. Truog WE, Sorensen GK, Standaert TA, Redding GJ 1986 Effects of the thromboxane synthetase inhibitor dazmegrel (UK 38,485) on pulmonary gas exchange and hemodynamics in neonatal sepsis. Pediatr Res 20:481-486

2. Runkle B, Goldberg RN, Streitfeld MM, Clark MR, Buron E, Stetzer ES, Bancalari E 1984 Cardiovascular changes in group B streptococcal sepsis in the piglet: response to indomethacin in relationship to prostacyclin and thrombaxane $\mathrm{A}_{2}$. Pediatr Res 18:874-878

3. Sorensen GK, Redding GJ, Truog WE 1985 Mechanisms of pulmonary gas exchange abnormalities during experimental group B streptococcal infusion. 
Pediatr Res 19:922-926

4. Rojas J, Larsson LE, Ogletree ML, Brigham KL, Stahlman MT 1983 Effect of cyclooxygenase inhibition on the response to group B streptococcal toxin in sheep. Pediatr Res 17:107-110

5. Goldberg RN, Suguihara C, Streitfeld MM, Bancalari A, Clark MR, Bancalari E 1986 Effects of a leukotriene antagonist on the early hemodynamic manifestations of group B streptococcal sepsis in piglets. Pediatr Res 20:1004-1008

6. Miller RR, Menke JA, Hansen NB, Zwick DL, Bickers RG, Nowicki PT 1986 The effect of naloxone on the hemodynamics of the newborn piglet with septic shock. Pediatr Res 20:707-710

7. Englehardt B, Sandberg K, Bratton D, Vandenabbeele A, Grogaard J, Hellerqvist C, Sundell H 1987 The role of granuloctyes in the pulmonary response to group B streptococcal toxin in young lambs. Pediatr Res 21:159-165

8. Kubo K, Kobayashi T 1985 Effects of OKY-046, a selective thromboxane synthetase inhibitor on endotoxin-induced lung injury in unanesthetized sheep sheep. Am Rev Respir Dis 132:494-499

9. Rojas J, Green RS, Hellerqvist CG, Olegard R, Brigham KL, Stahlman MT 1981 Studies on group B beta-hemolytic streptococcus. II. Effects on pulmonary hemodynamics and vascular permeability in unanesthetized sheep. Pediatr Res 15:899-904

10. Godal A, Belenky DA, Standaert TA, Woodrum DE, Grimsrud L, Hodson WA 1976 Application of the hot-wire anemometer to respiratory measurements in small animals. J Appl Physiol 40:275-277

11. Kuipers J, Sidi D, Heymann N, Rudolph AM 1982 Comparison of methods of measuring cardiac output in newborn lambs. Pediatr Res 16:594-598

12. Wagner PD, Saltzman H, West JB 1974 Measurement of continuous distribution ventilation perfusion ratios: theory. J Appl Physiol 36:588-599

13. Truog WE, Hlastala MP, Standaert TA, McKenna HP, Hodson WA 1979 Oxygen induced alteration of ventilation-perfusion relationship in rats. Appl Physiol 47:1112-1117

14. Hlastala MP, Robertson HT 1978 Inert gas elimination characteristics of the normal and abnormal lung. J Appl Physiol 44:258-266

15. Robertson HT, McKenna HP, Hlastala MP 1982 Influence of temperature and hemoglobin saturation on partition coefficients for three gases used for inert gas elimination studies. Physiologist 25:268(abstr)

16. MaClouf $\mathbf{J} 1982$ A radioimmunoassay for 6-keto-PGF ${ }_{1 \alpha}$. In: Lands WEM, Smith WL (eds) Prostaglandins and Arachidonate Metabolites. Methods of Enzymology, Vol 86. Academic Press, New York, pp 273-286

17. Fitzpatrick FA 1982 A radioimmunoassay for thromboxane $B_{2}$. In: Lands WEM, Smith WL (eds) Prostaglandins and Arachidonate Metabolites. Methods of Enzymology, Vol 86. Academic Press, New York, pp 286-297
18. Jaffe BM, Behrman HR (eds) 1974 Prostaglandins E A and F. In: Methods of Hormone Radioimmunoassay. Academic Press, New York, pp 19-34

19. Kessler DL, Truog WE, Murphy J, Standaert TA, Palmer S, Woodrum DE, Hodson WA 1982 Experimental hyaline membrane disease in the premature monkey: effects of antenatal dexamethasone. Am Rev Respir Dis 126:62

20. Zar JH 1974 Biostatistical Analysis. Prentice Hall, Englewood Cliffs, NJ, pp 105-114

21. Yam J, Roberts RJ 1980 Oxygen induced lung injury in the newborn piglet. Early Hum Dev 4:411-424

22. Julien M, Flick MR, Hoeffel JN, Murray JF 1984 Accurate reference measurement for post-mortem lung water. J Appl Physiol 56:248-253

23. Malik AB, vanderZee H, Newmann PH, Gertzberg NB 1980 Effects of pulmonary edema on regional perfusion in the intact dog lung. J Appl Physio 49:834-840

24. Sprague RS, Stephenson AH, Lonigro AJ 1984 Prostacyclin $I_{2}$ supports blood flow to hypoxic alveoli in anesthetized dogs. J Appl Physiol 56:1246-1251

25. Lawson JA, Patrono C, Ciabattoni G, Fitzgerald GA 1986 Long lived enzymatic metabolites of thromboxane $\mathrm{B}_{2}$ in the human circulation. Ann Biochem 155:198-205

26. Catella F, Healy D, Lawson JA, Fitzgerald GA 1986 Eleven dehydrothromboxane $\mathrm{B}_{2}$ : a quantitative index of thromboxane $\mathrm{A}_{2}$ formation in the human circulation. Proc Natl Acad Sci USA 83:5861-5865

27. Kapitan KS, Wagner PD 1987 Linear programming analysis of $V_{A} / Q$ distributions: average distribution. J Appl Physiol 62:1356-1362

28. Wagner PD, Gale GE, Moon RE, Torre-Bueno JR, Stolp BW, Saltzman HA 1986 Pulmonary gas exchange in humans exercising at sea level and simulated altitude. J Appl Physiol 61:260-270

29. Wagner PD, Hedenstierna G, Bylin G, Lagerstrand L 1987 Reproducibility of the multiple inert gas elimination technique. J Appl Physiol 62:1740-1746

30. Rendas A, Brauthwaite M, Reid L 1978 Growth of pulmonary circulation in normal pig-structural analysis and cardiopulmonary function. $J$ Appl Physio 451:806-81

31. Haworth SG, Hislop AA 1981 Adaptation of the pulmonary circulation to extra uterine life in the pig and its relevance to the human infant. Cardiovasc Rev 15:108-119

32. Stenmark KR, James SL, Voelkel NB 1983 Leukotriene C4-D4 in neonates with hypoxemia and pulmonary hypertension. N Engl J Med 309:77-80

33. Tracey KJ, Beutler B, Lowry SF, Merryweather J, Wolpe S, Milsark IW, Hariri RJ, Fahey III TJ, Zentella A, Albert JD, Shires GT, Cerami A 1986 Shock and tissue injury induced by Recombinant human cachectin. Science 234:470-474 